doi: $10.15407 /$ ujpe62.06.0502

L.A. BULAVIN, O.M. ALEKSEEV, YU.F. ZABASHTA, K.M. KOVALOV, M.M. LAZARENKO, S.YU. TKACHOV

Taras Shevchenko National University of Kyiv (64/13, Volodymyrs'ka Str., Kyiv 01601, Ukraine; e-mail: kovalovkostya@univ.kiev.ua)

\title{
PHASE TRANSITIONS
} PACS 71.20.Nr, 72.20.Pa AT DEHYDRATION OF GLUCOSE

\begin{abstract}
The dielectric constant of the glucose-water system has been studied in the temperature interval from -180 to $120^{\circ} \mathrm{C}$ and the frequency interval from 5 to $50 \mathrm{kHz}$. On the basis of the data obtained, the physical mechanism of dehydration of glucose has been proposed. The dehydration of glucose is shown to be a sequence of phase transitions: monohydrate-anhydride, fixed waterfree water, the appearance of a water film on the surface of the glucose-water system, and the subsequent water evaporation.
\end{abstract}

Keywords: phase transition, dehydration, dielectric permittivity, glucose.

\section{Introduction}

Researches of glucose properties have a long, almost two-century history. At the initial stage, they were a response to the demands of food industry. For this stage of researches, typical is work [1], in which a phase diagram for aqueous glucose solutions was obtained.

At the next stage, which lasts till now, the main aim of such researches became the solution of the problems posed by medicine before physics. Those problems can be conditionally divided into two groups. One of them includes problems associated with the fact that glucose is one of the components of a living organism. While solving those problems, the behavior of glucose as a part of a living organism is simulated by studying the properties of aqueous glucose solutions [2]. Problems associated with the manufacture of drugs in the form of pills or powders that include glucose as a component can be classified to another group. In this case, the issue of preserving

(C) L.A. BULAVIN, O.M. ALEKSEEV, YU.F. ZABASHTA, K.M. KOVALOV, M.M. LAZARENKO,

S.YU. TKACHOV, 2017

502 the quality of mentioned drugs in time is of importance, because glucose is known to intensively absorb moisture from the environment.

Hence, one can see that the indicated problems are based on the interaction between glucose and water, i.e. on the processes of hydration and dehydration of glucose. Earlier, the dehydration of glucose was studied by the methods of differential scanning calorimetry, x-ray diffraction, electron microscopy, optical spectroscopy, time-domain spectroscopy, and mass spectrometry [3-6]. In the cited works concerning the separate aspects of the physical mechanism of dehydration of glucose, the possibility to consider the "monohydrate-anhydride" transition as pseudopolymorphic was analyzed, the assumption was made about the existence of a vitrification transition, and so forth. However, the main issue remained unresolved: How is that or another examined aspect associated with water loss by glucose?

We did not manage to find publications, where the dehydration mechanism would be completely described. Therefore, the aim of this work was to establish the physical mechanism of dehydration of glucose. For this purpose, we use the dielectric method.

ISSN 2071-0194. Ukr. J. Phys. 2017. Vol. 62, No. 6 
The key argument in favor of this method is the fact that the dielectric permittivity of water exceeds the dielectric permittivity of glucose by more than an order of magnitude, so that the dielectric method is sensitive to the water content in the system.

\section{Experimental Results}

Glucose specimens with a water content of $6 \%$ were studied. The real, $\Delta \varepsilon^{\prime}$, and imaginary, $\varepsilon^{\prime \prime}$, parts of the complex dielectric permittivity were measured, by following the method described in works $[7,8]$. The results of measurements are shown in Figs. 1 and 2. In these figures, the value of dielectric permittivity at the temperature $T=-180{ }^{\circ} \mathrm{C}$ and the frequency $\nu=$ $=\omega / 2 \pi=5 \mathrm{kHz}$ was selected as a reference point.

In Fig. 1, the temperature dependences of the real part $\Delta \varepsilon^{\prime}$ of the complex dielectric permittivity of the specimen are depicted. As one can see, the temperature dependences reveal two maxima: at $T_{1}=$ $=45.0 \pm 0.5{ }^{\circ} \mathrm{C}$ and $T_{2}=94.0 \pm 0.5{ }^{\circ} \mathrm{C}$. Note that the positions of these maxima are not changed, when the frequency is varied.

In Fig. 2, the temperature dependences of the imaginary part $\varepsilon^{\prime \prime}$ of the complex dielectric permittivity of the specimen are shown. As one can see, the dependences for glucose with the $6 \%$ water content demonstrate similar maxima, whose positions coincide with the positions of maxima in the temperature dependences of the real part $\Delta \varepsilon^{\prime}$ of the complex dielectric permittivity.

From the physics of phase transitions [9], it is known that peaks with the attributes mentioned above appear only due to phase transitions. Hence, our measurements of the temperature dependence of the complex dielectric permittivity testify that phase transitions take place in the studied system at the temperatures indicated above. Let us analyze their nature.

\section{Thermodynamic Phases of the Glucose-Water System}

It is known [3] that glucose $\left(\mathrm{C}_{6} \mathrm{H}_{12} \mathrm{O}_{6}\right)$ and water can form a monohydrate with the chemical formula $\mathrm{H}_{2} \mathrm{O} \cdot \mathrm{C}_{6} \mathrm{H}_{12} \mathrm{O}_{6}$. In the case where the crystals of glucose do not contain water, this substance is called anhydride.

Besides two mentioned components, the examined specimens might contain both free water and the

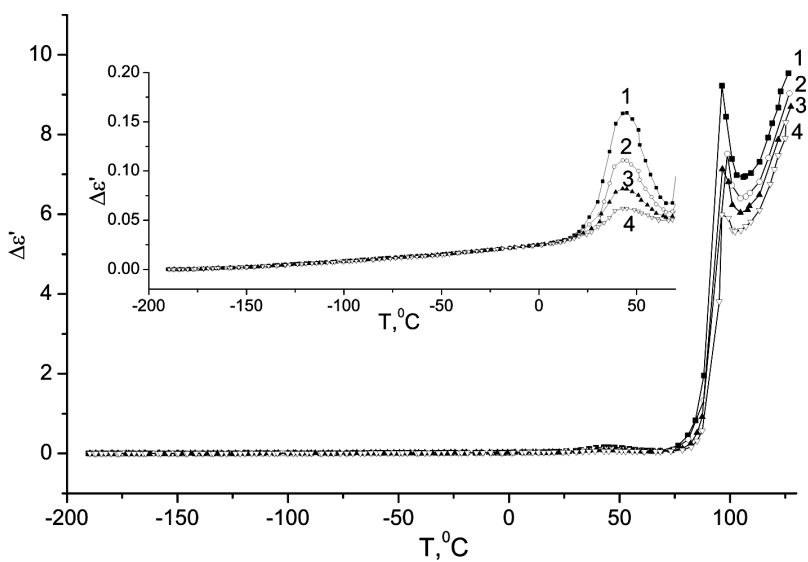

Fig. 1. Temperature dependences of the real part $\Delta \varepsilon^{\prime}$ of the complex dielectric permittivity of glucose with the $6 \%$ water content at the frequency $f=5(1), 10$ (2), 20 (3), and $50 \mathrm{kHz}(4)$

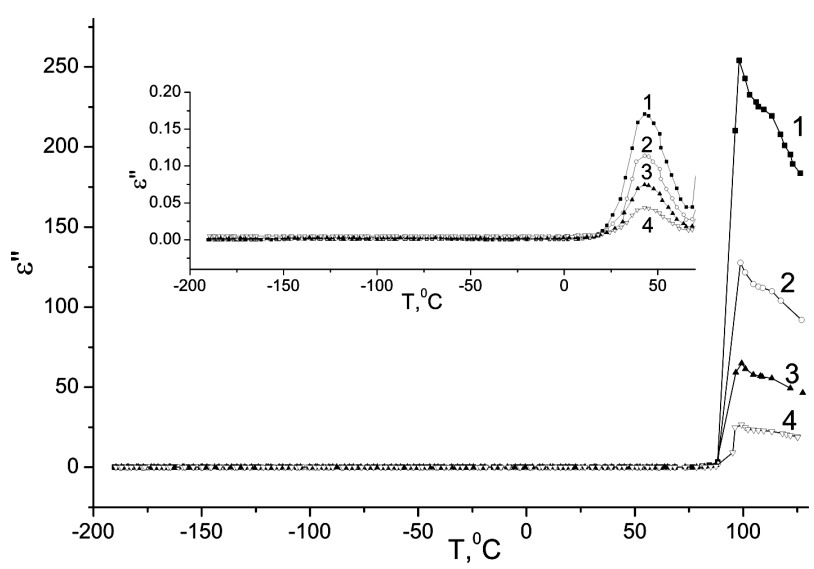

Fig. 2. Temperature dependences of the imaginary part $\varepsilon^{\prime \prime}$ of the complex dielectric permittivity of glucose with the $6 \%$ water content at the frequency $f=5$ (1), 10 (2), 20 (3), and $50 \mathrm{kHz}(4)$

aqueous glucose solution. All the indicated components can form thermodynamic phases of the glucosewater system. Accordingly, there can be phase transitions between those phases.

The transitions that take place in the glucose-water system are presented in the phase diagram shown in Fig. $3[10]$ in the coordinates temperature $T$ vs. the glucose concentration $C$. This phase diagram should be interpreted as follows. Branch $O M$ corresponds to the equilibrium between the solution and ice, branch $M N$ to the equilibrium between the solution and monohydrate, and branch $N P$ to the equilibrium between the solution and anhydride. 


\section{Monohydrate-Anhydride Transition}

According to the phase diagram depicted in Fig. 3, point $N$ is a point of phase transition monohydrateanhydride. This statement is confirmed by our experiment. Really, the temperature dependences of the real and imaginary parts of the dielectric permittivity have maxima at the temperature $T_{1}=45.0 \pm 0.5{ }^{\circ} \mathrm{C}$. The temperature position of those maxima does not depend on the frequency. This is typical of phase transitions. On the contrary, for the relaxation phenomena, as a rule, the temperature positions of relaxation peaks in similar systems depend on the frequency.

According to its chemical formula, monohydrate contains $90 \%$ of glucose. At the heating, the chemical composition of monohydrate is not changed. Therefore, its temperature behavior is described by line $R S$ shown in Fig. 3 up to the temperature $T_{1}$ of the monohydrate-anhydride phase transition. This temperature corresponds to the temperature coordinate of points $N$ and $S$ in the phase diagram. In the researched specimen, the glucose content amounted to $94 \%$. Therefore, the behavior of this system at the

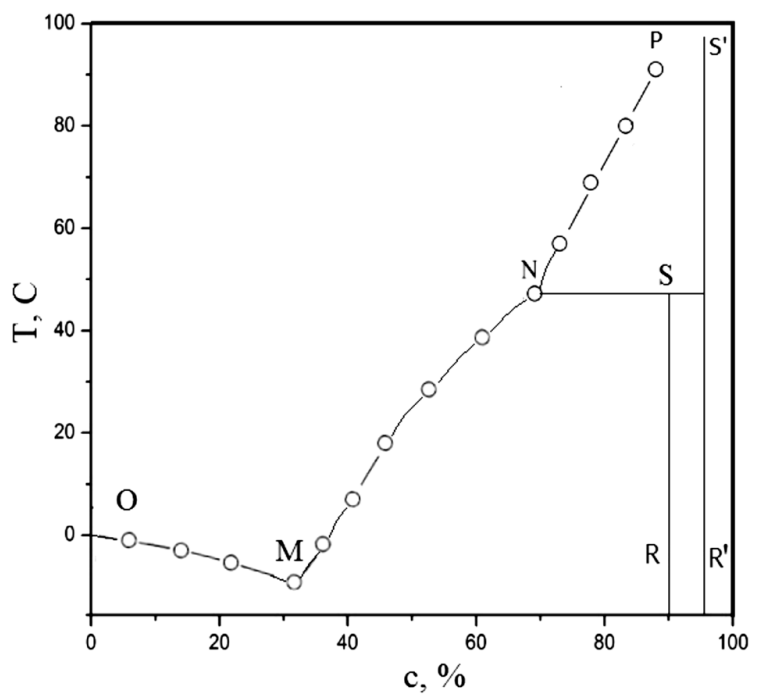

Fig. 3. Phase diagram of the glucose-water system
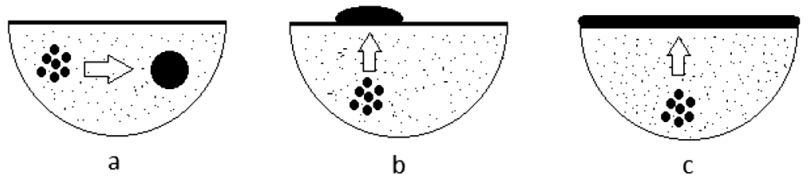

Fig. 4. Scenarios of free water formation $(a)$ in the bulk and $(b, c)$ on the surface of the system heating will be described by line $R^{\prime} S^{\prime}$. The analyzed system consists from monohydrate and anhydride at $T<T_{1}$ and from anhydride and the solution of water in glucose at $T>T_{1}$.

\section{Transition with the Formation of Free Water}

The phase diagram in Fig. 3 is confined by the temperature corresponding to point $P$. From our experimental data, it follows that a phase transition takes place at the temperature $T_{2}=94.0 \pm 0.5^{\circ} \mathrm{C}$. It is important that this transition is accompanied by an anomalous (by two orders of magnitude) growth of $\Delta \varepsilon^{\prime}$, which reaches the value $\Delta \varepsilon^{\prime}(T) \approx 10$. Taking into account that $\Delta \varepsilon^{\prime}(T) \approx 80$ for water, a conclusion can be drawn that the transition, which is observed in the glucose-water system at $T_{2}=94.0 \pm 0.5{ }^{\circ} \mathrm{C}$, is associated with the exit of water molecules from the solution composition and the formation of free water. In other words, the bound water $\rightarrow$ free water transition takes place. This is a phase transition of the first kind. According to the standard ideas [11], this transition has two stages: first, the fluctuationdriven formation of nuclei of a "new" phase (B) occurs in the "old" phase (A); then the nuclei grow further, which is accompanied by the transition of water molecules from the "old" phase (A) into the "new" phase (B).

In Fig. 4, a possible scenario of free water formation from the glucose solution is shown. The bold straight line corresponds to the plane surface of the system. Water molecules are exhibited as colored circles. The areas with free water are also tinted.

In the classical model of the theory of phase transitions, a spherical nucleus of phase (B), which has radius $r$, is formed in infinite phase (A) [11]. According to this model, the behavior of the system at the first stage is governed by the fact that the dependence of the thermodynamic potential $\Phi$ on the nucleus radius $r$ has a maximum at $r=r^{*}$. A nucleus with this radius is called critical. The number of critical nuclei, $J$, that emerge in a unit volume per unit time is determined by the formula [1]

$J=f \exp \left[-\frac{\Phi^{*}(T)}{k_{\mathrm{B}} T}\right]$,

where $f=f(T)$ is a certain function of the temperature.

ISSN 2071-0194. Ukr. J. Phys. 2017. Vol. 62, No. 6 
This scenario of the phase transition of the first kind can also be implemented in our case. The roles of phases (A) and (B) will be played by the solution of water in glucose and free water, respectively (Fig. 4, a).

The theory of phase transitions [11] also considers models, in which the nuclei of a new phase are formed at the surface of the system. Let us verify whether this variant of the phase transition of the first kind is realized in our case or not. A nucleus consisting of free water evidently has the shape of a spherical segment (Fig. 4, b). Let us introduce the following notations: $a$ is the radius of the spherical segment base; $h$ the spherical segment height; $\mu_{\mathrm{A}}$ and $\mu_{\mathrm{B}}$ are the chemical potentials of water molecule in phases $(\mathrm{A})$ and $(\mathrm{B})$, respectively; $\sigma_{\mathrm{AC}}, \sigma_{\mathrm{BC}}$, and $\sigma_{\mathrm{AB}}$ are the specific surface thermodynamic potentials at the interfaces phase (A)-gas, phase (B)-gas, and phase (A)-phase (B), respectively; and $\nu$ is the volume of a water molecule.

The area $S$ of the spherical segment surface and the spherical segment volume $V$ are determined by the formulas

$S=\pi\left(h^{2}+a^{2}\right)$,

$V=\frac{1}{6} \pi h\left(h^{2}+3 a^{2}\right)$.

For the increment of the thermodynamic potential $\Phi$ due to the formation of a nucleus of phase (B), we have

$\Phi=-\frac{1}{6} \frac{\pi h}{\nu}\left(h^{2}+3 a^{2}\right)\left(\mu_{\mathrm{A}}-\mu_{\mathrm{B}}\right)+$

$+\pi\left(h^{2}+a^{2}\right) \sigma_{\mathrm{BC}}-\pi a^{2}\left(\sigma_{\mathrm{AC}}-\sigma_{\mathrm{AB}}\right)$.

To find the maximum of $\Phi$, we should equate the first derivatives of $\Phi$ with respect to the variables $a$ and $h$ to zero:

$$
\begin{aligned}
& \frac{\partial \Phi}{\partial a}=\pi a\left[2\left(\sigma_{\mathrm{BC}}-\sigma_{\mathrm{AC}}+\sigma_{\mathrm{AB}}\right)-h \frac{\left(\mu_{\mathrm{A}}-\mu_{\mathrm{B}}\right)}{\nu}\right]=0 \\
& \frac{\partial \Phi}{\partial h}=\pi\left[2 \sigma_{\mathrm{BC}}-\frac{1}{2} a^{2} \frac{\left(\mu_{\mathrm{A}}-\mu_{\mathrm{B}}\right)}{\nu}-\right. \\
& \left.-\frac{1}{2} h^{2} \frac{\left(\mu_{\mathrm{A}}-\mu_{\mathrm{B}}\right)}{\nu}\right]=0 .
\end{aligned}
$$

From Eqs. (5) and (6), the $h$ - and $a$-values corresponding to the maximum $\Phi^{*}$ equal

$h=\frac{2 \nu\left(\sigma_{\mathrm{BC}}-\sigma_{\mathrm{AC}}+\sigma_{\mathrm{AB}}\right)}{\mu_{\mathrm{A}}-\mu_{\mathrm{B}}}$,
$a^{2}=h\left(\frac{\sigma_{\mathrm{BC}} \nu}{\mu_{\mathrm{A}}-\mu_{\mathrm{B}}}-h\right)$.

The specific surface thermodynamic potential at the solid-gas interface, $\sigma_{\mathrm{AC}}$, is known to substantially exceeds its counterparts at the liquid-gas, $\sigma_{\mathrm{BC}}$, and solid-liquid, $\sigma_{\mathrm{AB}}$, interfaces. Namely,

$\sigma_{\mathrm{AC}} \gg \sigma_{\mathrm{BC}} \gg \sigma_{\mathrm{AB}}$

Therefore, according to expressions (7) and (8), the following inequalities are satisfied:

$h<0$,

$a^{2}<0$.

From whence, it follows that, for real values of the parameters $a$ and $h$, the dependence $\Phi(a, h)$ given by formula (4) has no maximum. This fact means, in turn, that the phase transition takes place without the formation of critical nuclei (Fig. 4, b), and free water continuously spreads over the system surface to form a film (Fig. 4,c).

From the thermodynamic viewpoint, the absence of an energy barrier $\Phi^{*}$ is favorable for the latter scenario. Therefore, we may consider that the majority of water released from glucose due to the phase transition forms a film on the glucose surface.

\section{Evaporation of Free Water}

Our previous speculations may bring about an objection. Namely, water must begin to boil at a temperature of $100{ }^{\circ} \mathrm{C}$. However, no corresponding peak is observed in the $\varepsilon^{\prime \prime}(T)$ dependences at this temperature. Instead, the experimental data demonstrate a shoulder at a temperature of $110{ }^{\circ} \mathrm{C}$. In our opinion, this shoulder is a consequence of the mutual overlapping of two peaks: the previous one with the maximum at $94^{\circ} \mathrm{C}$ and a peak with the maximum at $110^{\circ} \mathrm{C}$ that is caused by the formation of vapor.

Let us apply the theory of phase transitions once more [11]. Now the matter concerns the liquid-gas transition. Accordingly, the critical nucleus is nothing else but a gas bubble. In accordance with the theory of phase transitions, we may assume that this nucleus is formed at the liquid-solid boundary. The contact angle of a bubble, $\theta$, is known to be determined by the formula

$\cos \theta=\frac{\sigma_{\mathrm{AB}}}{\sigma_{\mathrm{AC}}}-\frac{\sigma_{\mathrm{BC}}}{\sigma_{\mathrm{AC}}}$. 


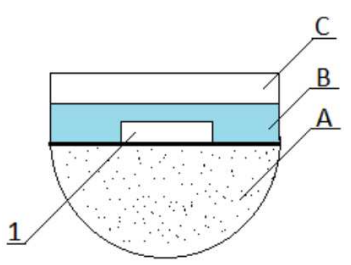

Fig. 5. Bubble in a water film: bubble (1), solid substrate (A), water film (B), vapor (C)

According to inequalities (9), the quantities $\sigma_{\mathrm{AB}} / \sigma_{\mathrm{AC}}$ and $\sigma_{\mathrm{BC}} / \sigma_{\mathrm{AC}}$ are small. In the zero approximation with respect to those quantities, we obtain the approximate equality

$\cos \theta \approx 0$,

which indicates that the bubble has the cylindrical shape (Fig. 5) with the generatrix directed perpendicularly to the surface of a solid substrate. Let $a_{1}$ stand for the cylinder radius, and $h_{1}$ the cylinder height. The change of the thermodynamic potential $\Phi_{1}$ due to the appearance of a bubble equals

$\Phi_{1}=-\frac{a_{1}^{2} \pi h_{1}}{\nu}\left(\mu_{\mathrm{B}}-\mu_{\mathrm{C}}\right)+\pi a_{1}^{2}\left(\sigma_{\mathrm{BC}}+\right.$

$\left.+\sigma_{\mathrm{AC}}-\sigma_{\mathrm{AB}}\right)+2 \pi a_{1}^{2} h_{1} \sigma_{\mathrm{BC}}$,

where $\mu_{\mathrm{C}}$ is the chemical potential of water molecules in vapor. We should equate the first derivatives of $\Phi_{1}$ with respect to $a_{1}$ and $h_{1}$ to zero:

$$
\begin{aligned}
& \frac{\partial \Phi_{1}}{\partial a_{1}}=\pi\left[2 a_{1}\left(\sigma_{\mathrm{AC}}+\sigma_{\mathrm{BC}}-\sigma_{\mathrm{AB}}\right)-\right. \\
& \left.-2 h_{1} a_{1} \frac{\mu_{\mathrm{B}}-\mu_{\mathrm{C}}}{\nu}+2 h_{1} \sigma_{\mathrm{BC}}\right]=0, \\
& \frac{\partial \Phi_{1}}{\partial h_{1}}=\pi\left[2 a_{1} \sigma_{\mathrm{BC}}-a^{2} \frac{\mu_{\mathrm{B}}-\mu_{\mathrm{C}}}{\nu}\right]=0 .
\end{aligned}
$$

The solution of the system of equations (15) and (16) looks like

$$
\begin{aligned}
a_{1}^{2} & =\frac{2 \sigma_{\mathrm{BC}} \nu}{\mu_{\mathrm{B}}-\mu_{\mathrm{C}}}, \\
h_{1} & =\frac{2 \nu\left(\sigma_{\mathrm{AC}}+\sigma_{\mathrm{BC}}-\sigma_{\mathrm{AB}}\right)}{\mu_{\mathrm{B}}-\mu_{\mathrm{C}}} .
\end{aligned}
$$

The analysis of formula (14) shows that the values of the parameters $a_{1}$ and $h_{1}$ determined by Eqs. (17) and (18) correspond to a saddle-like point. The value of $\Phi_{1}$ at this point,

$\Phi_{1}\left(a_{1}, h_{1}\right)=\frac{4 \sigma_{\mathrm{BC}}^{2}\left[\sigma_{\mathrm{BC}}+\sigma_{\mathrm{AC}}-\sigma_{\mathrm{AB}}\right]^{2} \nu^{2}}{\left(\mu_{\mathrm{B}}-\mu_{\mathrm{C}}\right)^{2}}$

plays the role of the energy barrier $\Phi^{*}$ in formula (1).

As is known from thermodynamics [11], the temperature $T_{0}$ of a phase transition (e.g., the transition of phase $\mathrm{B}$ into phase $\mathrm{C}$ ) is a temperature, at which both phases (B and $\mathrm{C}$ ) are in equilibrium. Therefore,

$\mu_{\mathrm{B}}=\mu_{\mathrm{C}}$

Here, we supposed that the mentioned phases are separated by an infinite plane.

Equality (20) corresponds to a situation where the phase transition has already terminated. However, when this transition only begins, the conditions to initiate a deviation from the equilibrium state must be created:

$\mu_{\mathrm{B}}>\mu_{\mathrm{C}}$

As a result, the phase transition is observed experimentally not at $T_{0}$, but at another temperature, $T_{10}$, which corresponds to the so-called border of metastability. By definition [12], this border is a deviation $\mu_{\mathrm{B}}-\mu_{\mathrm{C}}$ from the equilibrium, at which the number of critical nuclei $J$ formed in unit volume per unit time equals 1 :

$J=1\left[\mathrm{~cm}^{-3} \mathrm{~s}^{-1}\right]$.

Since $\Phi^{*}$ depends on $\mu_{\mathrm{B}}-\mu_{\mathrm{C}}$, we can determine the border of metastability by substituting $J=1$ into formula (1). As a result, we can find the phase transition temperature $T_{10}$ from the formula

$\mu_{\mathrm{B}}-\mu_{\mathrm{C}}=\lambda \frac{T_{10}-T_{0}}{T_{0}}$,

where $\lambda$ is the latent heat of evaporation per one molecule.

In our opinion, the speculations given above make it possible to draw a conclusion that the observed phase transition temperature $\left(110^{\circ} \mathrm{C}\right)$ is the temperature $T_{10}$ that corresponds to the border of metastability for the water-vapor transition under the conditions, when water forms a film. In the temperature interval $T_{0}<T<T_{10}$, we deal with overheated water. 


\section{Conclusions}

Our research makes it possible to assert that the dehydration of glucose is associated with a series of phase transitions.

First, the monohydrate-anhydride transition takes place in the glucose-water system at the temperature $T_{1}=45.0 \pm 0.5^{\circ} \mathrm{C}$. As a result, monohydrate loses water. Instead, the system is divided into two components: crystals of glucose anhydride and the solution of water in glucose.

If the temperature grows further, the amount of this solution increases, and the next phase transition takes place at the temperature $T_{2}=94.0 \pm 0.5^{\circ} \mathrm{C}$. As a result, water is released from the solution and forms a film on the surface of the system.

At the temperature $T_{3}=110.0 \pm 0.5{ }^{\circ} \mathrm{C}$, water is evaporated. Such an elevated value of the watervapor transition temperature is a consequence of the fact that water in the film becomes overheated owing to the nucleation at the boundary with the solid substrate.

1. R.F. Jackson, C.G. Silsbee.The solubility of dextrose in water. Sci. Papers Bureau Stand. 17, 715 (1922).

2. L.A. Bulavin, L.Yu. Vergun, Yu.F. Zabashta, K.O. Ogorodnik. Saccharide solutions under the action of a magnetic field. Ukr. J. Phys. 61, 583 (2016).

3. O. Giron. Investigations of polymorphism and pseudo-polymorphism in pharmaceuticals by combined thermoanalytical techniques. J. Therm. Anal. Cal. 64, 37 (2001).

4. M. Mathlouthi, G. Benmessaoud. B. Roge. Role of water in the polymorphic transitions of small carbohydrates. Food Chem. 132, 1630 (2012).
5. N.S. Trasi, S.X. Boerrigter, S.R. Byrn, T.M. Carvajal. Investigating the effect of dehydration conditions on the compactability of glucose. Int. J. Pharm. 406, 55 (2011).

6. H.B. Liu, X.C. Zhang. Dehydration kinetics of D-glucose monohydrate studied using $\mathrm{THz}$ time-domain spectroscopy. J. Chem. Phys. Lett. 429, 229 (2006).

7. A.N. Alekseev, M.M. Lazarenko, M.V. Lazarenko, K.N. Kovalev, S.Yu. Tkachev. Study of dielectric properties in region of liquid-solid phase transition. Zavod. Lab. Diagn. Mater. 82, No. 9, 43 (2016) (in Russian).

8. A.N. Alekseev, L.A. Bulavin, Y.F. Zabashta, S.Yu. Tkachev. Models of hydration and isomeric transitions of glucose molecules in aqueous solutions. Russ. J. Phys. Chem. A 88, 803 (2014).

9. E.M. Lifshitz, L.P. Pitaevsky, Physical Kinetics (Pergamon Press, 1979).

10. B.N. Stepanenko. The Course of Organic Chemistry (Vysshaya Shkola, 1981) (in Russian).

11. J. Frenkel, Kinetic Theory of Liquids (Dover, 1955).

12. M. Volmer, Kinetik der Phasenbuildung (Steinkopff, 1939).

Received 08.02.17.

Translated from Ukrainian by O.I. Voitenko

Л.А. Булавін, О.М. Алєксєєв, Ю.Ф. Забашта,

К.М. Ковалъов, М.М. Лазаренко, С.Ю. Ткачов

ФАЗОВІ ПЕРЕХОДИ

ПРИ ДЕГІДРАТАЦІЇ ГЛЮКОЗИ

$\mathrm{P}$ е $з$ ю м е

В інтервалі температур $-180-120{ }^{\circ} \mathrm{C}$ та інтервалі частот від 5-50 кГц досліджена діелектрична проникність системи глюкоза-вода. На основі отриманих даних запропоновано фізичний механізм дегідратації глюкози. Показано, що дегідратація глюкози є послідовністю фазових переходів: переходу “моногідрат-ангідрид”, переходу “зв'язана водавільна вода" з виникненням водяної плівки на поверхні системи глюкоза-вода з подальшим ㄲï випаровуванням. 